\title{
E-Transition Learning Objects
}

\author{
Nola Stair \\ The Business School
}

\section{Background}

New and continuing students, from a variety of cultural, educational and social backgrounds, often need more support to help ensure a smoother transition into higher education, as documented in several recent University of Greenwich induction reports (2008, 2009).

Many students are often overwhelmed by the volume of information provided during orientation. This results in a lack of understanding about academic content, confusion about course procedures, and loss of instructional time as the same information is then repeated by individual academic staff.

\section{Intended outcomes}

The goal of this University of Greenwich 2010 Dragons' Den-funded project was to provide clarification of concepts, constructs and other processes at the course/programme delivery level for Business School students by creating flexible E-Transition Learning Objects (LOs) that are not restricted by time, content, logistics and/or delivery channels (Collis \& Moonen, 2001).

Although the definition of LOs varies widely, as noted by Smith (2004), the context in which the term is used in this case study focuses on the development of multimedia elements (i.e. 'Just in Time' audio minilectures and video clips about relevant student-focussed topics) to enhance and support instruction. The university's managed learning environment (MLE, or portal) and virtual learning environment(VLE) would be used as flexible delivery channels to distribute engaging, meaningful and relevant resources for the ongoing transitional needs of students.

\section{The Challenge}

As one of five departments within the Business School, the Department of Systems Management \& Strategy (SMS) is responsible for delivering the BA Hons Business Studies programme locally and internationally. Nola Stair, Eleni Tzouramani and Petros leromanchou (in roles of SMS Year 1-2-3 Personal \& Professional Development (PPD) course leaders and Year 1-2-3 Induction co-ordinators) had already worked closely to analyse the needs of new (as well as continuing) students.

Their Dragons' Den funding included the hiring of two students to support the project during July/August 2010. The student workers assisted with the development of questions for use with Year 1-2-3 students during focus groups. The questions were aimed at new students' hesitation, frustration and uncertainty about university life. After the focus groups were held, the team reflected upon common issues and a matrix was developed to organise the key areas. After analysing the matrix of issues, some of the focus group participants were invited to provide brief videotaped tips about these topics, after which the video 
clips were exported to digital format using Windows Movie Maker and minor edits, such as adding text captions, were carried out. Finally, after review and testing, the clips were uploaded to a streaming media server so that their URLs could be linked to the virtual learning environment and/or university portal.

In addition, several course leaders used Echo 360 (a lecture capture system) to develop audio minilectures about their courses, highlighting key points raised by the student focus groups. Although the Echo 360 system was installed in several campus locations, the team made use of Echo 360's personal capture software, which can be installed on individual laptops or workstations. The user-friendly Echo 360 interface enabled course leaders to self-create their learning objects with little or no training.

Following the sharing of experiences, listening to students through focus groups and discussing ideas for engaging and retaining students, a series of audio mini-lectures and video clips was designed and developed around topics, such as 'Personal Journeys with Learning Disabilities' and 'Being Proactive During your 1st Year'. Examples of video clip topics and student presenters are shown in Figure 1 below.

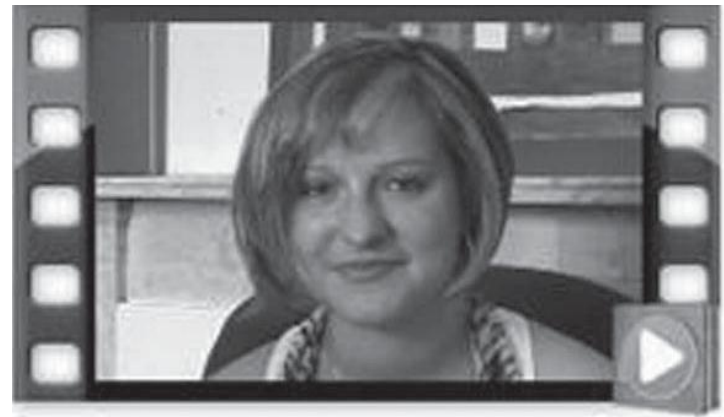

Being proactive during your first year

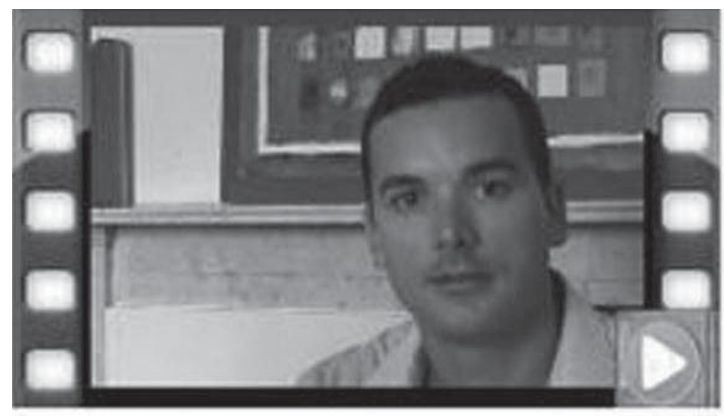

Avoiding extenuating circumstances

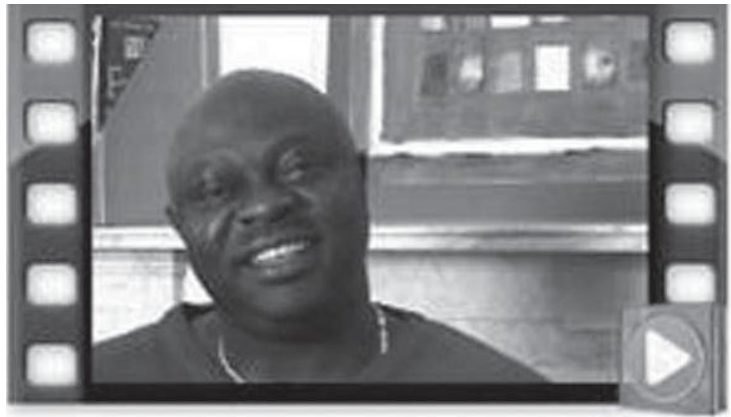

Experiences from study skills workshops in the library

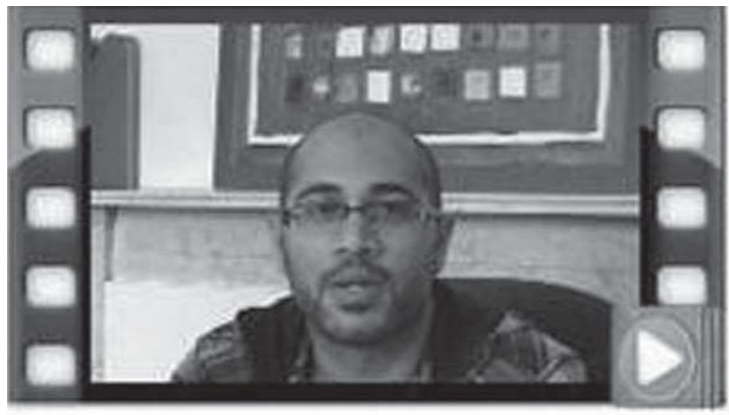

Importance of presentation skills

Figure 1 Video examples - student testimonials and/or advice 
During late August/early September, links to the student video tips were added to several courses hosted in the university's VLE for piloting during weekly tutorial lessons. The next stage of development involved using information and instructional design concepts to create a channel within the university's portal and organise the LOs into appropriate categories, as shown in Figure 2. This additional delivery mechanism allowed students to access the LOs without having to log in to a specific course. The university's Web Services department provided a short demonstration on this surprisingly easy-to-use tool.

\section{Established practice}

At the beginning of the term, students have to choose between two Year 3 capstone courses Consultancy and Thematic Independent Studies. However, written information sent by the Business School office often did not provide students with a 'real sense' of the actual course expectations and requirements. LOs, in the form of (1) audio-narrated presentations by both course leaders and (2) student video tips/advice about both courses, were made available and enabled students to make 'more informed' choices based on previous students' real experiences. See the topic Year 3 - Which is right for me? shown in Figure 2.

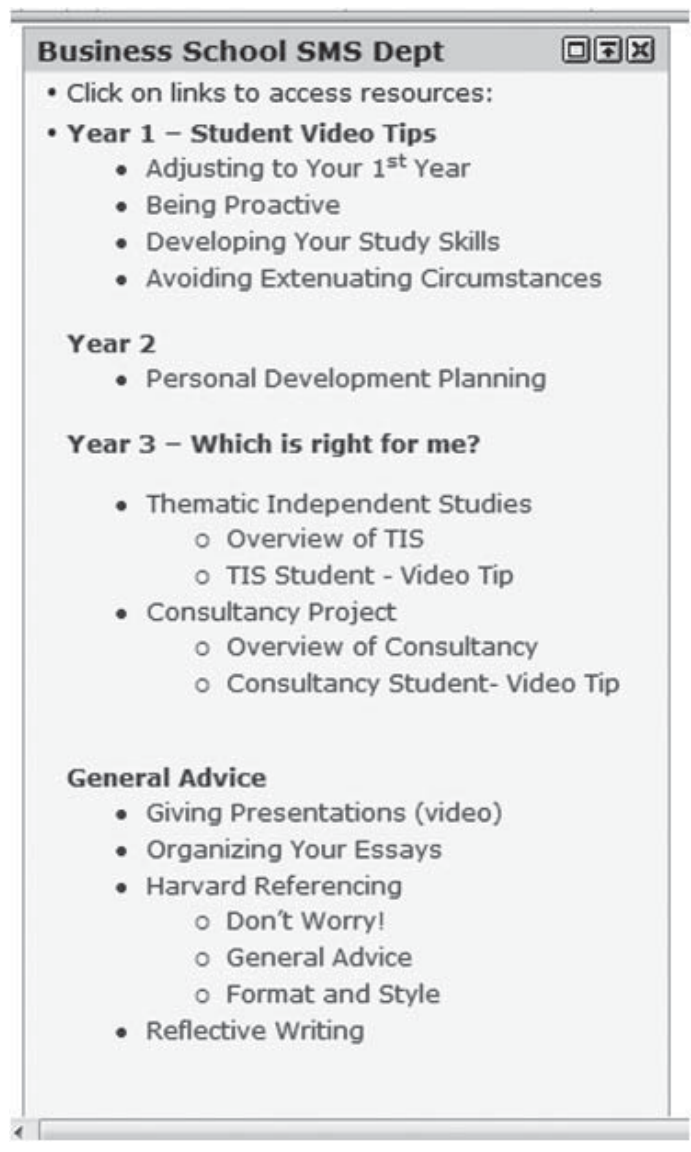

Figure 2 E-transition portal channel
In addition, other programme leaders were able to present the Year 3 Consultancy and Thematic Independent Studies LOs during separate orientations for returning students and for direct entry students. This again allowed students to reflect upon previous student experiences before making their own final decisions.

Course leaders were also able to direct late-arriving students to these same resources, which minimised ongoing repetition by embedding the links to these LOs in response to e-mailed requests for information.

\section{Unexpected benefits}

While the initial focus was to support the transitional needs of BA Hons Business Studies Years 1-2-3, the Year 3 e-transition LOs were also provided to the Department of Systems Management \& Strategy's international partners in Hong Kong, South Africa, Tanzania and Zambia to alleviate confusion about these two courses. An unseen benefit was that many of the e-transition LOs have also been useful at the MBA level, due to the sizeable international student population who require the same type of meaningful engagement opportunities to support their understanding of UK university expectations and procedures. In addition, unexpected LOs were created for other academic and administrative information that 
needed to be better timed, and repeated or reinforced, throughout the year. This was also noted for Year 3 direct entry students who often need the same type of learning experiences and personal engagement with tutors that Year 1 students receive (University of Greenwich, 2009).

\section{Conclusions and recommendations}

This project has enabled a better understanding of the difficulties that new students encounter, as well as the needs of returning students. Ongoing results are being categorised in three areas:

\section{Academic}

Reusability of e-transition LOs during Open Days and with international partner course delivery

- Increased engagement and interest from academics not familiar with learning objects.

\section{Administrative}

- Noticeable decrease in the number of 'Year 3 course change forms' submitted by students

- Noticeable decrease in questions from late-arriving students about Year 3 course options.

\section{Technology}

- Awareness of the channel development within the Managed Learning Environment (MLE) - the university's portal - for distributing academic information on a wider scale. See Figure 3 for the combined project results.

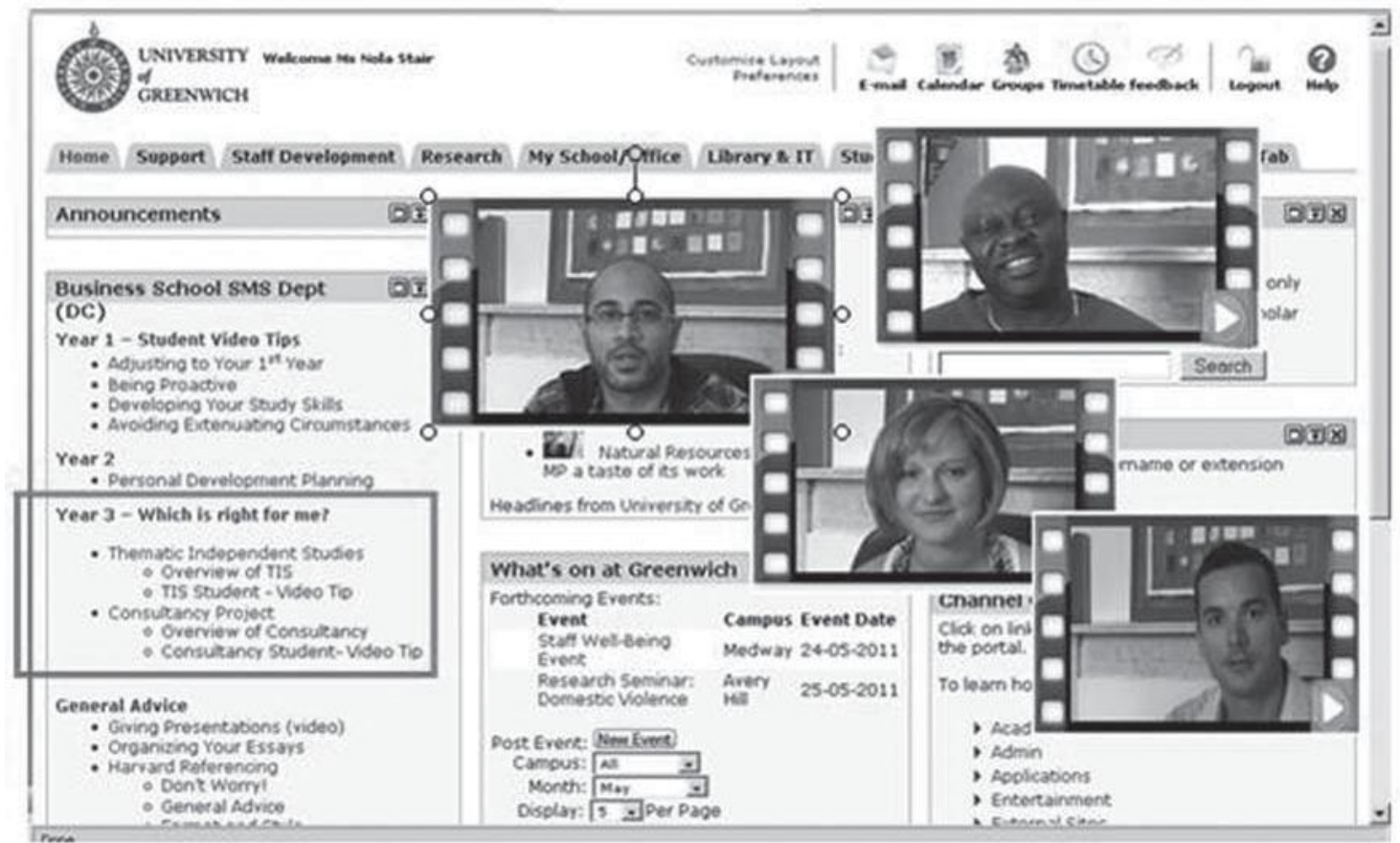

Figure 3 University of Greenwich portal with e-transition portal channel 
While the e-transition LOs continue to be piloted and integrated into specific learning activities for orientation, tutorials and individual lecturer/student use, the need remains to uncover additional aspects of student frustration and uncertainties about university life in order to continue developing more e-transition LOs. Interest has been expressed by other academics regarding expansion into other content areas.

As Eleni Tzouramani pointed out during the team's Dragons' Den pitch, research shows that an effective induction strategy can reduce withdrawal rates but also provide students with the confidence to achieve better results at university. The 're-usable learning objects' that this project created will be valuable 'available-on-demand' sources of information that are given as alternative learning resources to account for differing learning styles. Ongoing research and development will be important to analyse the instructional impact of e-transition LOs in helping to avoid the over-reliance on written and verbal information for students who have different learning styles and levels of English.

Results from the project were shared with the University of Greenwich's New Arrivals group in February 2011 and discussions have begun with the Business School's New Arrivals co-ordinator, regarding additional School funding for continuation. Funding was used to pay the student workers and provide book vouchers for focus group/interview participants. No additional software or hardware was purchased for this project. The team used existing equipment and tools (i.e. video cameras, Echo360 Lecture Capture System and Windows Movie Maker) to develop the e-transition LOs.

If you have access to the University of Greenwich portal, please feel free to view the e-transition LOs channel by following the steps below:

Log into http://portal.gre.ac.uk

Select Customise Layout

Click New Channel

- Select Academic as category

Select Business School SMS Dept as the channel

Then click Add Channel

\section{References}

Colis, B. and Moonen, J. (2001) Flexible Learning in a Digital World: Experiences and Expectations. London: Kogan-Page.

Smith, R. (2004) Guidelines for Authors of Learning Objects. Available at: <http://archive2.nmc.org/ guidelines/NMC\%20LO\%20Guidelines.pdf> [Accessed 1 March 2011].

University of Greenwich (2008) Student Induction: Guidelines for Academic Staff.

University of Greenwich (2009) Student Induction: Guidelines for Academic Staff. 